\title{
Long-run equilibria with borrowing constraints and altruism
}

\author{
John Laitner* \\ University of Michigan, Ann Arbor, MI 48109, USA \\ Received October 1990, final version received November 1991
}

This paper adapts a nonstochastic overlapping generations model to include liquidity constraints and intergenerational altruism. Existing work indicates the importance of both but often considers them separately. This paper studies their interactions. First, it shows that they tend to conflict - the model only admits stationary equilibria with dynastic wealth accumulation but no binding liquidity constraints, or with binding constraints but no dynastic accumulation. Second, it examines the latter type of equilibrium closely. If liquidity constraints bind, quantitative examples imply that consequent utility losses may be small and that economywide wealth accumulation tends to be unrealistically low.

\section{Introduction}

This paper is about two possible additions to a conventional overlapping generations model: lifetime liquidity constraints and intergenerational altruism. For the former, suppose bankruptcy laws lead creditors to demand tangible collateral for all loans. ${ }^{1}$ Then households will have to maintain nonnegative asset positions at all times and will be able to follow separate consumption and earnings paths only over the period until a liquidity constraint next binds. There are many potential consequences: Dolde (1978) and Mariger (1986) show that lifetime constraints might significantly increase the response of aggregate consumption to a temporary tax change; Hubbard and Judd $(1986,1987)$ show that constraints can increase the disutility of social security taxes and reduce their impact on saving; and, Becker (1980),

\footnotetext{
* I owe special thanks to the referees of this journal for many helpful comments on an earlier draft of this paper.

${ }^{1}$ This paper takes this legal system as given. The general approach contrasts to, for example, Yotsuzuka (1987).
} 
Loury (1981), and others trace the effects of borrowing constraints on investments in human capital and the distribution of income. Empirical studies often raise the suspicion that liquidity constraints influence the behavior of a noticeable segment of the population - e.g., Hall and Mishkin (1982), Hayashi (1985), Mariger (1987), Zeldes (1989), Jappelli (1990), and Campbell and Mankiw (1990). There seems to be evidence of significant intergenerational transfers as well - see Kotlikoff and Summers (1981), Kurz (1984), Cox (1987), and Gale and Scholz (1991). Modifying a life-cycle framework to model them may influence its implications rather dramatically: intergenerational linkages via transfers can lead to Ricardian neutrality, with notable consequences for the analysis of social security and national debt [see Barro (1974)]; the locus of private sector desired stationary-state wealth holdings may become perfectly interest-elastic at the 'modified golden rule' level [see Blanchard and Fischer (1989, ch. 2) and fig. 1 below]; and intergenerational connections conceivably mitigate the burdens of lifetime liquidity constraints [see, for instance, Hall (1986)]. Also, while the overlapping generations model has difficulty explaining observed quantities of wealth [see Kotlikoff and Summers (1981) and Kotlikoff (1988)], bequest-related savings might make up the shortfall.

This paper has two purposes. Presuming altruism and liquidity constraints are both realistic, it first attempts to show that we should study them jointly. Existing work has done this to an extent - showing, for example, that liquidity constraints on children may induce larger transfers from their parents than otherwise [see Altig and Davis (1989, sect. 4)]. This paper emphasizes the opposing nature of the two: altruism tends to lengthen time horizons for utility maximization; liquidity constraints do the reverse. Section 2 shows that the set of possible steady-state equilibria for our model fully mirrors the conflict: long-term equilibria exist in which liquidity constraints never bind or in which constraints bind regularly within every line of descent, but no equilibria simultaneously include binding liquidity constraints and long-horizon 'operational' connections within family lines. If a system is to explain both dynastic behavior and binding borrowing constraints, it would seem to require a degree of heterogeneity among consumers beyond differing birth dates.

Second, this paper analyzes in detail the steady states above with binding constraints. 'Interior solution' equilibria have attracted a great deal of attention - see Barro (1974) and the representative agent formulations in Blanchard and Fischer (1989). Cases with binding constraints tend to receive less notice in the theoretical literature, however. Yet, they have quite different characteristics. Section 3 calls attention to some of the differences and to both similarities and contrasts to overlapping generations models with no altruism. Section 4 considers the quantitative properties of equilibria with binding constraints. One finding is that implied wealth accumulations are 
disappointingly low - with, somewhat surprisingly, altruism partly to blame. A second is that utility losses from binding liquidity constraints tend to be smaller than specifications without altruism might lead one to suspect.

Intergenerational transfers in this paper stem exclusively from altruism. While parents could derive pleasure from the size of their bequest alone, the framework here assumes they care about their descendants' consumption possibilities. This paper's specification of preferences makes altruism twosided: parents and their adult children overlap in life for a number of periods; during the overlap, children are concerned about their parents, as well as parents about their children. The degree of altruism is strong: each household in a line of descent cares about its ancestors and descendants as much as itself. This is virtually opposite to the overlapping generations model - in which parents abruptly stop caring about their childrens' consumption as the latter become adults. It does seem to have some intuitive appeal, and it yields key simplifications to the analysis below.

\section{The household sector}

As stated, this paper's model combines elements from life-cycle and representative agent frameworks. In terms of the former, an equal and large number of families of each age $s \in[0,2 \cdot T]$ comprise the economy. For the latter, each household cares about the consumption possibilities of its descendants and ancestors in addition to its own. This paper focuses exclusively on stationary-state growth. In such equilibria, which section 3 discusses in more detail, the net-of-tax interest rate, $r$, and next-of-tax wage per 'effective' labor unit, $w$, are constant.

Begin with the life-cycle part of the framework. The model has only one consumption good; its price is 1 at all dates. There are borrowing constraints ruling out negative net worth. Individual families live $2 \cdot T$ years. Time is continuous. Adult children and their parents overlap in life for $T$ years. In section 5 , for instance, a family begins with a 20 -year-old male and female; two children are born after five years; the parents are 45 when the children leave home to form their own families; and, the parents can live an additional 26 years - dying as their children's children become adults and form new families. There is no population growth.

A household with consumption $c(s)$ at age $s \in[0,2 \cdot T]$ derives a corresponding utility flow $u(c(s), s)$. All families have the same function $u(\cdot)$. Assume

$$
u(c, s)=h(s) \cdot(1 / \beta) \cdot c^{\beta}, \quad \beta \neq 0, \beta<1,
$$

or

$$
u(c, s)=h(s) \cdot \ln (c),
$$


where $h(\cdot)$ is exogenously given, piecewise twice continuously differentiable, and strictly positive. Section 5 uses $h(\cdot)$ to register life-cycle variations in family composition. The elasticity of marginal substitution for consumption between time periods is

$$
\sigma \equiv 1 /(1-\beta)
$$

For the sake of simplicity, omit the separate logarithmic case below.

A household's utility from its own lifetime consumption combines flows for ages 0 to $2 \cdot T$. Let $\delta \geq 0$ be the subjective discount rate and

$$
\Delta \equiv \mathrm{e}^{-\delta \cdot T}
$$

Then letting $U^{1}$ and $U^{2}$ be the first and second half of lifetime utility for the household above,

$$
\begin{aligned}
U^{1}+\Delta \cdot U^{2} \equiv & \int_{0}^{T} \mathrm{e}^{-\delta \cdot s} \cdot u(c(s), s) \mathrm{d} s \\
& +\Delta \cdot \int_{T}^{2 \cdot T} \mathrm{e}^{-\delta \cdot(s-T)} \cdot u(c(s), s) \mathrm{d} s
\end{aligned}
$$

Notice that $U^{1}+\Delta \cdot U^{2}$ is only part of the household's total utility - the contribution related to descendants and predecessors is incorporated below.

A household of age $s$ inelastically supplies $l(s)$ natural labor units. If the time is $t$, technological change yields

$$
\mathrm{e}^{\gamma \cdot t} \cdot l(s), \quad \gamma>0
$$

'effective' labor units. Earnings abilities are identical among families of the same age and cohort. Assume that $l(\cdot)$ is piecewise continuously differentiable and that for some interval of ages $[0, \bar{s}], l(s)>0$.

Turning to altruism, for simplicity think of a patrilineal (or, alternatively, parthenogenetic) system: in their first $T$ years parents raise a boy and a girl; in the following $T$ years the children are adults and only the boy's household remains a concern to his parents - conversely, only the boy feels continuing responsibility for the parents. Laitner (1991) uses a noncooperative gametheoretic model to show that symmetric concern for offspring coupled with nonrandom mating can lead to the same type of analytical framework.

Consider a single family (tracing descent patrilineally). Let the utility of the line's $i$ th generation from its own lifetime consumption be $U^{1 i}+\Delta \cdot U^{2 i}$. The consumption is $c^{i}(s), s \in[0,2 \cdot T]$. Let the same household's total utility, including the portion which it derives from the consumption of its descen- 
dants and ancestors, be

$$
W^{i} \equiv \sum_{j=-\infty}^{\infty} \Delta^{(j-i)} \cdot\left[U^{2 j}+U^{1, j+1}\right]
$$

Letting

$$
{ }_{i} \vec{c}=\left\{\left\{c^{k}(s), s \in[0,2 \cdot T]\right\}_{-\infty<k<i},\left\{c^{i}(s), s \in[0, T]\right\}\right\}
$$

and

$$
\vec{c}_{i}=\left\{\left\{c^{i}(s), s \in[T, 2 \cdot T]\right\},\left\{c^{k}(s), s \in[0,2 \cdot T]\right\}_{i<k<\infty}\right\}
$$

$W^{i}=W^{i}\left({ }_{i} \vec{c}, \overrightarrow{c_{i}}\right)$. The consumption path $\left({ }_{i} \vec{c}, \vec{c}_{i}\right)$ is feasible if it satisfies all budget and liquidity constraints spelled out below. If at date $t$ the generation $i$ family is age $T,{ }_{i} \vec{c}$ is already past - hence fixed. This paper assumes that at date $t$ in that event the family line's household of generation $i$ wants a feasible $\overrightarrow{c_{i}}$ with

$$
W^{i}\left({ }_{i} \vec{c}, \vec{c}_{i}\right)-W^{i}\left({ }_{i} \vec{c}, \vec{c}_{i}^{*}\right) \geq 0, \text { all feasible } \vec{c}_{i}^{*}
$$

This paper also assumes that the family line's generation $i+1$ household at the same time wants a feasible $\vec{c}_{i}$ with

$$
W^{i+1}\left({ }_{i} \vec{c}, \vec{c}_{i}\right)-W^{i+1}\left({ }_{i} \vec{c}, \vec{c}_{i}^{*}\right) \geq 0, \text { all feasible } \vec{c}_{i}^{*}
$$

Notice that since (4)-(5) are presented in terms of 'overtaking' criteria, their individual $W^{i}$ and $W^{i+1}$ components need not be bounded. In fact, at time $t$ utility flows for ${ }_{i} \vec{c}$ are irrelevant in this formulation.

Lines (4)-(5) incorporate two-sided altruism of the high degree outlined in the introduction: in each, $U^{2 j}$ and $U^{1, j+1}$ receive the same weight; thus, a young family in generation $i+1$ cares about the concurrent consumption of its parents as if the latter consumption were its own, and the parents care about the consumption of their adult (male) child as if it were their own. Also, households apply the same subjective discount rate to all future utility flows within their line of descent as to their lifetime $u\left(c^{i}(s), s\right)$.

The geometric nature of subjective discounting in the definition of $W^{i}$ avoids the time consistency problems discussed by Strotz (1956). Since adult children and their parents have the same criteria - other than a constant of proportionality - this paper's formulation also escapes the consistency problems for concurrent generations in Hori and Kanaya (1989, sect. VIII). [Note that Hori and Kanaya would classify (4)-(5) as a special case of 'paternalistic' 
preferences.] In fact, at time $t$ above, (4)-(5) imply both generations can be thought of as wanting to maximize

$$
\sum_{j=i}^{\infty} \Delta^{(j-i)} \cdot\left[U^{2 j}+U^{1, j+1}\right]
$$

Thus, (6) is an ordinal representation of the preferences of each of the two generations over consumption figures yet to be determined.

One alternative specification of preferences would have parents care about their children but not about their predecessors - see, for instance, Altig and Davis (1989). Given multi-period overlaps between parents and their adult children in the present paper, however, 'single-sided altruism' would potentially complicate the analysis significantly: in place of the joint maximization in (9) below, motivated by this paper's high degree of reciprocal altruism, a $T$-period Stackelberg game would emerge - with parents the 'leaders' and their children the 'followers'. Children might behave strategically - fully consuming their earnings early in marriage, for example, in order to extract large transfers when the arrival of their own children raised their households' marginal utility of wealth. Even if parents could somehow 'precommit' their transfers, year-by-year liquidity constraints for all parties [see (7)-(8) below] would tend to make the game more difficult to work with than (9). A lower degree of 'two-sided altruism' than this paper's would tend to introduce complexities even with one-period overlaps. For example, parents might try to consume their earnings early in life in order to extract larger inter vivos transfers from their (reluctant) children later [see Lindbeck and Weibull (1988), Laitner (1988), and Bruce and Waldman (1990)].

To characterize behavior, continue to focus on the single line of descent above. The following treatment proceeds in three steps: first it determines households' consumption conditional on inter vivos transfers and bequests, second it determines transfers conditional on bequests, and third it determines bequests themselves.

Above, generation $i$ is age $T$ at date $t$. Suppose the latter household's assets at each age $s$ are $a^{i}(s)$. Let the household's transfers to its adult son be $\vec{x}^{i}=\left\{x^{i}(s)\right\}_{s \in[T, 2 \cdot T]}$ and the transfers it receives from the child $\vec{z}^{i+1}=$ $\left\{z^{i+1}(s)\right\}_{s \in[0, T]}$. Then from ages $T$ to $2 \cdot T$, conditional on $\vec{x}^{i}$, its bequest $b^{i}$, and its assets at age $T$, say $\mathrm{e}^{\gamma \cdot t} \cdot A^{i}$, generation $i$ will want to solve

$$
v_{i t}^{\text {old }}\left(\vec{x}^{i}, \vec{z}^{i+1}, A^{i}, b^{i}\right) \equiv \max _{c^{i}(s)} \int_{T}^{2 \cdot T_{-}} \mathrm{e}^{-\delta \cdot(s-T)} \cdot u\left(c^{i}(s), s\right) \mathrm{d} s,
$$


subject to

$$
\begin{aligned}
& \frac{\mathrm{d} a^{i}(s)}{\mathrm{d} s}=r \cdot a^{i}(s)+w \cdot \mathrm{e}^{\gamma \cdot(t+s-T)} \cdot l(s)-c^{i}(s)-x^{i}(s) \\
& \quad+z^{i+1}(s-T), \quad s \in[T, 2 \cdot T], \\
& \begin{aligned}
a^{i}(s) \geq 0, \quad s \in[T, 2 \cdot T], \\
a^{i}(T)=\mathrm{e}^{\gamma \cdot t} \cdot A^{i} \quad \text { and } \quad a^{i}(2 \cdot T)=b^{i} .
\end{aligned}
\end{aligned}
$$

Given bankruptcy laws, this paper assumes financial markets enforce $a^{i}(s) \geq$ 0 . The criterion of (7) follows from (6).

With corresponding notation, generation $i+1$ in the same line contemporaneously wants to solve, conditional on $\vec{x}^{i}, \vec{z}^{i+1}, b^{i}$, and $A^{i+1}$,

$$
v_{i+1, t}^{\text {young }}\left(\vec{x}^{i}, \vec{z}^{i+1}, b^{i}, A^{i+1}\right) \equiv \max _{c^{i+1}(s)} \int_{0}^{T} \mathrm{e}^{-\delta \cdot s} \cdot u\left(c^{i+1}(s), s\right) \mathrm{d} s
$$

subject to

$$
\begin{aligned}
& \frac{\mathrm{d} a^{i+1}(s)}{\mathrm{d} s}=r \cdot a^{i+1}(s)+w \cdot \mathrm{e}^{\gamma \cdot(t+s)} \cdot l(s)-c^{i+1}(s) \\
& +x^{i}(s+T)-z^{i+1}(s), \quad s \in[0, T], \\
& a^{i+1}(s) \geq 0, \quad s \in[0, T], \\
& a^{i+1}(0)=0 \quad \text { and } \quad a^{i+1}(T)+b^{i}=\mathrm{e}^{\gamma \cdot(t+T)} \cdot A^{i+1} \text {. }
\end{aligned}
$$

To determine $\vec{x}^{i}$ and $\vec{z}^{i+1}$, conditional on $A^{i}$ and $A^{i+t}$, consider the joint maximization problem

$$
\begin{aligned}
v_{i t}\left(A^{i}, A^{i+1}\right) \equiv & \max _{c^{i+1}(s), c^{i}(s+T), s \in[0, T]} \int_{0}^{T} \mathrm{e}^{-\delta \cdot s} \cdot u\left(c^{i+1}(s), s\right) \mathrm{d} s \\
& +\int_{T}^{2 \cdot T} \mathrm{e}^{-\delta \cdot(s-T)} \cdot u\left(c^{i}(s), s\right) \mathrm{d} s,
\end{aligned}
$$


subject to

$$
\begin{aligned}
\dot{a}(s)= & r \cdot a(s)+w \cdot \mathrm{e}^{\gamma \cdot(t+s)} \cdot[l(T+s)+l(s)] \\
& -c^{i}(s+T)-c^{i+1}(s), \quad s \in[0, T], \\
a(s) \geq & 0, \quad s \in[0, T], \\
a(0)= & \mathrm{e}^{\gamma \cdot t} \cdot A^{i} \quad \text { and } \quad a(T)=\mathrm{e}^{\gamma \cdot(t+T)} \cdot A^{i+1}
\end{aligned}
$$

Call (9) the 'joint problem for generation $i$ '. It has a unique solution - see Mariger (1987) for an algorithm. Insert the solution path for $c^{i}(s)$ from (9) into the accounting equation for $a^{i}(s)$ in (7). Set $x^{i}(s)=0$ and $z^{i+1}(s-T)=0$ for the moment. If $a^{i}(s) \geq 0$ is violated at $s \in[T, 2 \cdot T]$, raise $z^{i+1}(s-T)$ just enough to make $a^{i}(s)=0$. Then insert $c^{i+1}(s)$ from (9) into the accounting equation for (8). Set $z^{i+1}(s)$ as above and initially let $x^{i}(s+T)=0$. Whenever $a^{i+1}(s) \geq 0$ is violated, raise $x^{i}(s+T)$ just enough to relieve it. Given the constraints in (9), the constructed $x^{i}(s+T)$ and $z^{i+1}(s)$ must lead to feasible $a^{i}(s)$ and $a^{i+1}(s)$ paths for (7)-(8) - with $a^{i}(2 \cdot T)=b^{i}$ in (7) determining $b^{i}$.

The consumption saving and inter vivos transfers just derived maximize $U^{2 i}+U^{1, i+1}$ in (6) for the family line. [The maximized value is $v_{i t}\left(A^{i}, A^{i+1}\right)$.] The outcome specified in the preceding paragraph would emerge if household $i$ and its adult son pooled their resources from $t$ to $t+T$ and cooperated fully. Or, with $A^{i}$ and $A^{i+1}$ specified and the constraints of (7)-(8), it would be the payoff-dominant Nash equilibrium for a game from $t$ to $t+T$ between generation $i$ - allowed to choose $b^{i} \geq 0, c^{i}(s)$, and $a^{i}(s)$ $\geq 0$, and $x^{i}(s) \geq 0$ all $s \in[T, 2 \cdot T]-$ and generation $i+1$ - allowed to choose $c^{i+1}(s), a^{i+1}(s) \geq 0$, and $z^{i+1}(s) \geq 0$ all $s \in[0, T]$. This paper assumes that given $A^{i}$ and $A^{i+1}$, the outcome just described does prevail each $i$.

For the last stage of the characterization of behavior, note that $A^{i}$ is given (from past decisions) at time $t .^{2}$ Let $V_{i t}\left(A^{i}\right)$ be the best value for (6) which generation $i$ at time $t$ thinks it can obtain. Let

$$
\Gamma \equiv \mathrm{e}^{\beta \cdot \gamma \cdot T} .
$$

Given (1) and (6),

$$
v_{i+1, t+T}\left(A, A^{*}\right)=\Gamma \cdot v_{i t}\left(A, A^{*}\right) .
$$

\footnotetext{
${ }^{2}$ Note that $\mathrm{e}^{\gamma \cdot t} \cdot A^{i}$ in (9) consists of the sum of the accumulated life-cycle savings generation $i$ carries at age $T$ and the bequest of generation $i-1$. (This paper assumes that bequests never 'skip generations': if generation $i-1$ in a family line leaves an estate or makes an inter vivos gift, generation $i$ is the recipient.)
} 
Accordingly, assume generation $i$ believes

$$
V_{i+1, t+T}(A)=\Gamma \cdot V_{i t}(A) \text {. }
$$

Then with time consistency, assume generation $i$ believes as well

$$
V_{i t}\left(A^{i}\right)=\max _{A^{i+1} \geq 0}\left\{v_{i t}\left(A^{i}, A^{i+1}\right)+\Delta \cdot \Gamma \cdot V_{i t}\left(A^{i+1}\right)\right\} .
$$

Finally, appendix 1 constructs upper and lower bounds, $V^{\mathrm{U}}(A)$ and $V^{\mathrm{L}}$ such that feasibility alone requires

$$
\mathrm{e}^{\beta \cdot \gamma \cdot t} \cdot V^{\mathrm{L}} \leq V_{i t}\left(A^{i}\right) \leq \mathrm{e}^{\beta \cdot \gamma \cdot t} \cdot V^{\mathrm{U}}\left(A^{i}\right) \text { for all } A^{i} \geq 0 .
$$

For any given $w$ and $r$, the household sector portion of this paper's model then seeks to derive a time path of $A^{i}$ 's from (10)-(11) and of consumption and inter vivos transfers from (6)-(9) - as outlined after (9).

\section{Stationary equilibria}

This paper considers only stationary equilibria. There is no government debt. The economy is closed. The features defining a stationary equilibrium are: (i) $r$ and $w$ are independent of time; (ii) the aggregate 'effective' labor supply, $E_{t}$ at time $t$, grows at geometric rate $\gamma$; and (iii) the aggregate wealth stock, $K_{t}$ at time $t$, grows at the same rate $\gamma$. Construction guarantees item (ii):

$$
E_{t}=E_{0} \cdot \mathrm{e}^{\gamma \cdot t} \text { for all } t .
$$

Without sacrificing generality normalize

$$
E_{0}=1 \text {. }
$$

This section examines our framework's stationary equilibria. There are three cases. Defining $r^{*}$ from

$$
\sigma \cdot\left(r^{*}-\delta\right)=\gamma,
$$

$r^{*}$ is the 'modified golden-rule interest rate - see Blanchard and Fischer (1989). The three possibilities are: $r>r^{*}, r=r^{*}$, and $r<r^{*}$. For future reference, let

$$
H(r) \equiv\left(\mathrm{e}^{-\delta \cdot T} \cdot \mathrm{e}^{r \cdot T}\right)^{\sigma} / \mathrm{e}^{\gamma \cdot T},
$$

so that $H(r)<1$ iff $r<r^{*}, H\left(r^{*}\right)=1$, and $H(r)>1$ iff $r>r^{*}$. 
If $r$ exceeds $r^{*}$, families will desire time paths of consumption which rise faster than the rate of technological progress (think, for example, of a conventional representative agent model with $\gamma=0$ and $r>\delta$ ). Thus, a stationary equilibrium with $r>r^{*}$ is impossible. Formally:

Proposition 1. No stationary state exists with $r>r^{*}$.

Proof. Consider any family line. Using the envelope theorem, the first-order condition for a bequest from generation $i$ to generation $i+1-$ see (9)-(10) - yields

$$
h(T) \cdot\left[c^{i}(T)\right]^{\beta-1} \geq h(0) \cdot\left[c^{i+1}(0)\right]^{\beta-1},
$$

with equality in the event of a positive transfer. The first-order condition for lifetime optimization yields

$$
h(0) \cdot\left[c^{i}(0)\right]^{\beta-1} \geq \mathrm{e}^{r \cdot T} \cdot \mathrm{e}^{-\delta \cdot T} \cdot h(T) \cdot\left[c^{i}(T)\right]^{\beta-1},
$$

with equality if lifetime constraints do not bind at any age. Combining the two expressions, and noting that $\beta-1<0$,

$$
c^{i}(0) \leq\left[\mathrm{e}^{r \cdot T} \cdot \mathrm{e}^{-\delta \cdot T}\right]^{-\sigma} \cdot c^{i+1}(0) .
$$

Hence,

$$
H(r) \cdot c^{i}(0) \leq c^{i+1}(0) \cdot \mathrm{e}^{-\gamma \cdot T} .
$$

Then $H(r)>1$ implies

$$
c^{i}(0)<c^{i+1}(0) \cdot \mathrm{e}^{-\gamma \cdot T} .
$$

Aggregate steady-state consumption divided by $K_{t}$ must equal the constant

$$
\left(r \cdot K_{t}+w \cdot E_{t}-\dot{K}_{t}\right) / K_{t}=r+w \cdot\left(E_{t} / K_{t}\right)-\gamma .
$$

A constant growth rate $\gamma$ for $K_{t}$ is thus inconsistent with (12).

A stationary equilibrium can exist with $r=r^{*}$. Without technological change, this is the familiar case with the interest rate equaling the subjective discount rate. Somewhat surprisingly, in any such equilibria none of the inequality constraints in $(9)-(10)$ bind - and this is true despite that fact that our model does not have a single representative agent: at any date, the economy contains households of all ages. 
Proposition 2. Let $\Delta \cdot \Gamma<1$. Let $r=r^{*}$. There exists $\kappa^{*}<\infty$ such that private wealth accumulation can sustain $K_{t} /\left(\omega \cdot E_{t}\right)=\kappa$, any $\kappa$ above $\kappa^{*}$. In any such state, the inequality constraints of $(9)-(10)$ never bind.

Proof. Assume $\Delta \cdot \Gamma<1$. Let $r=r^{*}-$ so that $H(r)=1$. First we show that inequality constraints do not bind.

Consider a stationary equilibrium. For any given family line and generation $i$, first-order conditions yield (as in the preceding proof)

$$
\begin{aligned}
h(0) \cdot\left[c^{i}(0)\right]^{\beta-1} & \geq \mathrm{e}^{(r-\delta) \cdot s} \cdot h(s) \cdot\left[c^{i}(s)\right]^{\beta-1} \\
& \geq \mathrm{e}^{(r-\delta) \cdot T} \cdot h(T) \cdot\left[c^{i}(T)\right]^{\beta-1} \\
& \geq \mathrm{e}^{(r-\delta) \cdot T} \cdot h(0) \cdot\left[c^{i+1}(0)\right]^{\beta-1} \text { for all } s \in[0, T] .
\end{aligned}
$$

If lifetime liquidity constraints bind for generation $i$ in its youth, the first three terms in (14) are not all equal; if the nonnegativity constraint $A^{i} \geq 0$ binds, the last two are unequal - see (9).

Suppose all terms in (14) are equal - so that the dynasty in question is not liquidity-constrained as it passes through generations $i-1$ and $i$. Then $H(r)=1$ implies

$$
c^{i}(0)=c^{i+1}(0) \cdot \mathrm{e}^{-\gamma \cdot T} .
$$

The dynasty will face the same problem one generation later, except $\mathrm{e}^{\gamma \cdot T}$ will multiply earnings, consumption, and assets; hence, given homothetic preferences, the dynasty will not be constrained as it passes from generation $i$ to $i+1$. Continuing, once (15) holds for a family line in one generation, it holds in all subsequent generations.

The alternative to (15), given $H(r)=1$, is

$$
c^{i}(0)<c^{i+1}(0) \cdot \mathrm{e}^{-\gamma \cdot T} .
$$

But, (16) cannot hold in all family lines, or (16) in some and (15) in others, if we have a stationary equilibrium - see the last step of the proof of Proposition 1.

Thus, in a stationary equilibrium (15) must hold for all families. We have noted that (15) can only emerge when no lifetime or intergenerational inequality constraints bind.

The existence portion of the proof appears in appendix 2 . 
Household-sector behavior will also allow stationary equilibria if $r<r^{*}$, although 'operative' dynastic connections disappear completely:

Proposition 3. Let $\Delta \cdot \Gamma<1$. For $r<r^{*}$, suppose that economy has rested in a stationary state for many periods. Then there is some s such that every family is liquidity-constrained at age $s$.

Proof. Suppose we have a stationary state with $r<r^{*}$. Consider any family line, and any generation $i$, currently of age $T$. Let the time be $t=T$ as well. There are four cases:

(1) Suppose the liquidity constraint in (9) binds at age $s$ in the joint problem of generation $i$, and suppose the same held in generation $i-1$. Then with homotheticity we have a solution for the family line: the asset profile repeats itself, multiplied by $\mathrm{e}^{\gamma \cdot T}$, generation after generation - always dipping to zero at age $s$. (Notice that if generation $i$ is constrained at age $s$, generation $i-1$ is concurrently constrained at age $s+T$. As the pattern repeats, generation $i$ is constrained at $s+T$.)

(2) Suppose the constraint binds at age $s$ in the joint problem of generation $i$ but that assets in the line were positive $T$ years before. Note that chosen asset profiles will always be continuous.

Consider fig. 1. Path $A B C D$ is the family line's solution. Derive the line's optimal solution had assets been zero at age $s$ in generation $i-1$. Consider possible solutions in that event represented by the dotted lines from $E$. Since the upper one crosses $A B C D$, two distinct solutions emanate from $B$. This is impossible given our strictly concave preferences. Thus, the dotted solution must resemble $E F C$ - in that it must meet the abscissa at $C$. But then $E F C$, multiplied by $\mathrm{e}^{\gamma \cdot T}$, must give the solution after $C$. In other words, after $C$ we must enter case (1). So, if the stationary state has persisted more than one period, the family line must be in case (1).

(3) Suppose the liquidity constraint in (9) does not bind during the joint problem of generation $i-1$ but the constraint $A^{i} \geq 0$ binds. Then set $s=T$ and repeat cases (1) and (2).

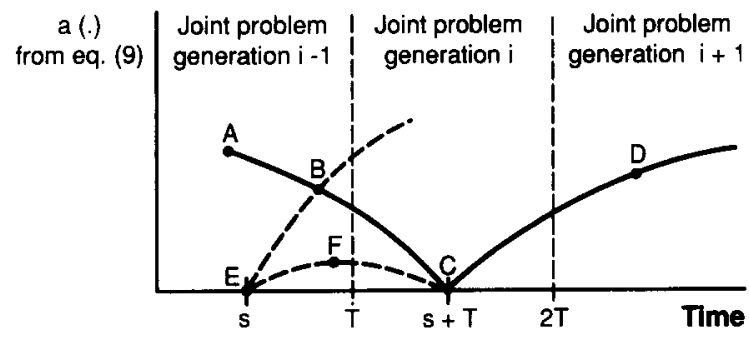

Fig. 1. Utility-maximizing family asset profiles. 
(4) Suppose the liquidity constraint of (9) does not bind during the joint problem of generation $i-1$ and that $A^{i}>0$.

As in the preceding proofs,

$$
H(r) \cdot c^{i-1}(0)=c^{i}(0) \cdot \mathrm{e}^{-\gamma \cdot T}
$$

Since $H(r)<1$ here,

$$
c^{i-1}(0)>c^{i}(0) \cdot \mathrm{e}^{-\gamma \cdot T}
$$

If this inequality persists, over time consumption in the family line will become miniscule relative to earnings. Hence, asset accumulation must begin at some point. After accumulations have become very large, utility maximization will demand more consumption. Thus case (4) cannot persist indefinitely. When we leave case (4), we have just seen we end in case (1) - which is permanent.

Hence, in a persisting stationary state, all family lines must be in case (1). Suppose two lines have different $s$ values. As in fig. 1, the asset profiles cannot cross without being the same. So, there must be at least one common liquidity-constrained age. Thus, in a persisting stationary state, there exists an $s$ such that every family unit drops to zero assets at age $s$ [and so, as in case (1), at age $s+T$ as well].

The following proposition provides an additional characterization if $r<r^{*}$. Appendix 2 provides a proof.

Proposition 4. Let $\Delta \cdot \Gamma<1$. Fix some $r<r^{*}$. Suppose that the economy has rested in a stationary state for many periods. Then there is a unique solution to (10)-(11). The right-hand side of (10) defines a unique function $\phi(\cdot)$ with $A^{*}=\phi(A)$. There is a unique $A^{\mathrm{FP}} \geq 0$ such that $A^{\mathrm{FP}}=\phi\left(A^{\mathrm{FP}}\right)$. In a persisting stationary state, each $A^{i}$ in (10) equals $A^{\mathrm{FP}}$ - for all $i$ and all family lines. Thus, in this case there is one and only one stationary-state ratio $K_{t} /\left[\omega \cdot E_{t}\right]$ consistent with household-sector utility maximization.

Fig. 2 summarizes Propositions 1-4. For each $r$ and $w$, the $S$ curve graphs time-invariant ratios $K_{t} /\left[\omega \cdot E_{t}\right]$ consistent with private-sector utility maximization.

With $r>r^{*}$, saving across generations is so attractive that wealth accumulation is unlimited - in other words, there can be no stationary equilibrium with $r>r^{*}$.

For $r=r^{*}$, a 'permanent income' result holds: family lines want to equalize consumption at each given age, normalized for technological progress, across generations; hence, normalized dynastic wealth remains 


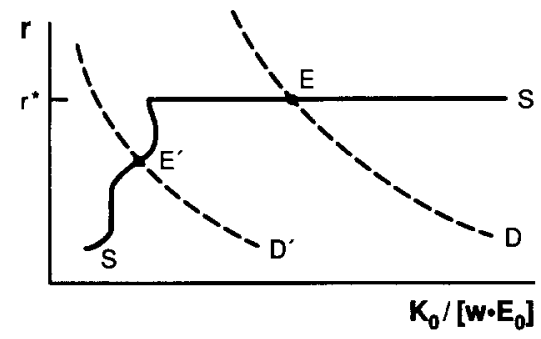

Fig. 2. The supply and demand for wealth.

constant - each household consumes during its lifetime only its own labor earnings plus the interest in excess of rate $\gamma$ on its inherited wealth. Any aggregate amount of wealth sufficient to insure that lifetime liquidity constraints never bind (within any family line) is sustainable in a stationary equilibrium - leading to the flat part of $S$.

For $r<r^{*}$, Proposition 3 shows that dynastic wealth accumulation disappears. Proposition 4 shows the $S$ curve associates a single $K_{t} /\left[w \cdot E_{t}\right]$ with each $r$.

An aggregate production function and an assumption of competitive factor pricing can complete the model. For example, suppose that net national product of $Q_{t}$ and that

$$
Q_{t}=\theta \cdot\left[K_{t}\right]^{\alpha} \cdot\left[E_{t}\right]^{1-\alpha}, \quad \alpha \in(0,1) .
$$

Then competitive factor markets yield

$$
\left(r_{t} \cdot K_{t}\right) /\left(w_{t} \cdot E_{t}\right)=\alpha /(1-\alpha) .
$$

The latter gives the demand curve $D$ (or $D^{\prime}$ ) in fig. 2. $E$ and $E^{\prime}$ are then the possible stationary equilibria.

In closing this section, compare Propositions 1-4 with Altig and Davis (1989, prop. 2). As stated above, Altig and Davis in effect assume one-period overlaps between parents and adult children and employ single-sided altruism. Conversely, their analysis allows the degree of altruism to be a parameter. Despite the differences, their Proposition 2 equilibria all have interest rates bounded above by $r^{*}-$ as in Proposition 1 above; when liquidity constraints bind in Altig and Davis [Proposition 2(ii)-(iii)], the interest rate is below $r^{*}$-as in this paper's Propositions 2-3; and they focus on the role and importance of inter vivos transfers - just as this paper does. In contrast, Altig and Davis highlight the way in which liquidity needs can augment transfer activity, while the next two sections below tend to stress the conflicting nature of the two. 
Table 1

Stationary equilibria with double- and triple-family composites.

\begin{tabular}{|c|c|c|c|c|c|}
\hline \multirow[b]{2}{*}{ Trial } & \multirow[b]{2}{*}{ Parameters } & \multicolumn{3}{|c|}{ Wealth-to-GNP ratios } & $A>0^{\mathrm{a}}$ \\
\hline & & $\begin{array}{c}\text { Life-cycle } \\
\text { model }\end{array}$ & $\begin{array}{c}\text { Life-cycle } \\
\text { model with } \\
\text { liquidity } \\
\text { constraints }\end{array}$ & \multicolumn{2}{|c|}{$\begin{array}{l}\text { Intergenerational } \\
\text { life-cycle model } \\
\text { with liquidity } \\
\text { constraints }\end{array}$} \\
\hline \multicolumn{6}{|c|}{ Double-family composites (maximum adult life $s p a n=52$ years) } \\
\hline $\begin{array}{l}1 \\
2 \\
3 \\
4 \\
5 \\
6 \\
7 \\
8 \\
9\end{array}$ & $\begin{array}{l}\beta=-1, r=0.00 \\
\beta=-1, r=0.03 \\
\beta=-1, r=0.06 \\
\beta=-3, r=0.00 \\
\beta=-3, r=0.03 \\
\beta=-3, r=0.06 \\
\beta=-9, r=0.00 \\
\beta=-9, r=0.03 \\
\beta=-9, r=0.06\end{array}$ & $\begin{array}{l}-2.842 \\
-1.551 \\
-0.510 \\
-2.842 \\
-2.078 \\
-1.470 \\
-2.842 \\
-2.378 \\
-1.970\end{array}$ & $\begin{array}{l}0.157 \\
0.271 \\
0.447 \\
0.156 \\
0.202 \\
0.246 \\
0.156 \\
0.163 \\
0.168\end{array}$ & $\begin{array}{r}0.025 \\
0.268 \\
\text { NA } \\
0.025 \\
0.096 \\
0.257 \\
0.025 \\
0.035 \\
0.065\end{array}$ & $\begin{array}{l}\text { no } \\
\text { yes } \\
\text { NA } \\
\text { no } \\
\text { no } \\
\text { yes } \\
\text { no } \\
\text { no } \\
\text { no }\end{array}$ \\
\hline \multicolumn{6}{|c|}{ Triple-family composites (maximum adult life $\mathrm{span}=60$ years) } \\
\hline $\begin{array}{l}10 \\
11 \\
12 \\
13 \\
14 \\
15 \\
16 \\
17 \\
18\end{array}$ & $\begin{array}{l}\beta=-1, r=0.00 \\
\beta=-1, r=0.03 \\
\beta=-1, r=0.06 \\
\beta=-3, r=0.00 \\
\beta=-3, r=0.03 \\
\beta=-3, r=0.06 \\
\beta=-9, r=0.00 \\
\beta=-9, r=0.03 \\
\beta=-9, r=0.06\end{array}$ & $\begin{array}{l}-3.094 \\
-1.435 \\
-1.006 \\
-3.094 \\
-2.172 \\
-1.455 \\
-3.094 \\
-2.586 \\
-2.127\end{array}$ & $\begin{array}{l}0.306 \\
0.535 \\
0.818 \\
0.306 \\
0.401 \\
0.492 \\
0.306 \\
0.326 \\
0.340\end{array}$ & $\begin{array}{r}0.139 \\
0.281 \\
\text { NA } \\
0.139 \\
0.194 \\
0.265 \\
0.139 \\
0.154 \\
0.174\end{array}$ & $\begin{array}{l}\text { yes } \\
\text { yes } \\
\text { NA } \\
\text { yes } \\
\text { yes } \\
\text { yes } \\
\text { yes } \\
\text { yes } \\
\text { yes }\end{array}$ \\
\hline
\end{tabular}

${ }^{\mathrm{a}}$ See line 18.

${ }^{\mathrm{b}}$ Cases with $r>r^{*}$.

The tables select parameter values familiar from the existing life-cycle literature and consistent with U.S. growth during the comparatively halcyon postwar period ending in the early 1970s.

For the rate of labor-augmenting technological change, table 1 sets $\gamma=$ 0.0187 - see Denison (1979, table 8-4). Table 2 considers a lower rate as well. A high rate tends to give young families a more important share of total of resources, consumption, and saving. It also makes earnings profiles rise more steeply with age. On balance, a lower $\gamma$ pushes the supply curve of fig. 2 to the right in our examples.

The exogenous function $h(s)$ in (1) can capture life-cycle changes in family composition. Following Tobin (1967), if $n(s)$ is the number of 'equivalent adults' in a household of age $s$, set

$$
h(s)=[n(s)]^{1-\beta} \quad \text { for all } \quad s \in[0,2 \cdot T] .
$$


Table 2

Alternative parameter choices $(\beta=-3$ and $r=0.03$, unless otherwise noted).

\begin{tabular}{|c|c|c|c|c|c|}
\hline \multirow[b]{2}{*}{ Trial } & \multirow[b]{2}{*}{$\begin{array}{c}\text { Parameter } \\
\text { changes }\end{array}$} & \multicolumn{3}{|c|}{ Wealth-to-GNP ratios } & $A>0$ \\
\hline & & $\begin{array}{l}\text { Life-cycle } \\
\text { model }\end{array}$ & $\begin{array}{l}\text { Life-cycle } \\
\text { model with } \\
\text { liquidity } \\
\text { constraints }\end{array}$ & $\begin{array}{r}\text { Interg } \\
\text { life-cy } \\
\text { with } \\
\text { con }\end{array}$ & $\begin{array}{l}\text { ational } \\
\text { model } \\
\text { idity } \\
\text { ints }\end{array}$ \\
\hline \multicolumn{6}{|c|}{ Double-family composites (maximum adult life span $=52$ years) } \\
\hline $\begin{array}{l}1 \\
2 \\
3 \\
4 \\
5 \\
6 \\
7\end{array}$ & $\begin{array}{l}\text { Mariger's } N(\cdot)^{\mathrm{a}} \\
\text { No mortality }^{\mathrm{b}} \\
\gamma=0.01 \\
\tau=0.22^{\mathrm{c}} \\
\delta=0.01, r=0.00 \\
\delta=0.01, r=0.03 \\
\delta=0.01, r=0.06\end{array}$ & $\begin{array}{l}-2.102 \\
-2.168 \\
-1.458 \\
-1.932 \\
-3.050 \\
-2.248 \\
-1.618\end{array}$ & $\begin{array}{l}0.103 \\
0.460 \\
0.282 \\
0.175 \\
0.134 \\
0.180 \\
0.223\end{array}$ & $\begin{array}{l}0.025 \\
0.183 \\
0.300 \\
0.081 \\
0.019 \\
0.051 \\
0.196\end{array}$ & $\begin{array}{c}\text { yes } \\
\text { no } \\
\text { yes } \\
\text { no } \\
\text { no } \\
\text { no } \\
\text { yes }\end{array}$ \\
\hline \multicolumn{6}{|c|}{ Triple-family composites (maximum adult life $\mathrm{span}=60$ years) } \\
\hline $\begin{array}{r}8 \\
9 \\
10 \\
11 \\
12 \\
13 \\
14\end{array}$ & $\begin{array}{l}\text { Mariger's } N(\cdot)^{\mathrm{a}} \\
\text { No mortality } \\
\gamma=0.01 \\
\tau=0.22^{\mathrm{c}} \\
\delta=0.01, r=0.00 \\
\delta=0.01, r=0.03 \\
\delta=0.01, r=0.06\end{array}$ & $\begin{array}{l}-2.392 \\
-2.572 \\
-1.344 \\
-2.071 \\
-3.388 \\
-2.407 \\
-1.656\end{array}$ & $\begin{array}{l}0.130 \\
0.610 \\
0.551 \\
0.335 \\
0.266 \\
0.358 \\
0.447\end{array}$ & $\begin{array}{l}0.222 \\
0.124 \\
0.296 \\
0.178 \\
0.124 \\
0.172 \\
0.235\end{array}$ & $\begin{array}{l}\text { yes } \\
\text { yes } \\
\text { yes } \\
\text { yes } \\
\text { yes } \\
\text { yes } \\
\text { yes }\end{array}$ \\
\hline
\end{tabular}

${ }^{a}$ Following Mariger (1986, ch. 7) we weight children and teens 0.3 and adults 65 -year-old and over 0.5 .

${ }^{\mathrm{b}}$ Both adults in every family live exactly $2 \cdot T$ years.

${ }^{\mathrm{c}} \mathrm{See}$ our construction of $l(s)$ in section 5 .

Assume each household begins with a 20 -year-old male and female. After an interval described below they have two children. The children leave home to form their own families when they reach age 20. Families have access to, and fully utilize, actuarially fair annuities and life insurance. Standard tables provide mortality rates (for men and women separately.) For simplicity this paper's calculations omit child mortality. Table 1 uses Tobin's numerical weights: $n(s)$ equals the survival probability (to family age $s$ ) of the household's adult male, plus the same for the spouse, plus 0.6 times the current number of minor children, plus 0.8 times the number of teenagers. Table 2 experiments with estimated weights from Mariger (1986) and with omitting adult mortality.

Fig. 3 graphs the equivalent adults profiles which tables 1 and 3-4 use. As outlined in section 2, table 1 assumes households have their children after five years. The diagram includes individual family profiles, $n(s)$, for $2 \cdot T=52$ and 60; the $n(s)+n(s+T)$ profile for a 'unit', as in (9), composed of a young and old family, with $T=26$; and the profile for a triple unit. The last allows 


\section{Equilibria with $r<r^{*}$}

This section considers the implications of Propositions 2-4 - especially the latter two - in more detail.

For stationary equilibria with $r=r^{*}$, Proposition 2 shows that, as in conventional representative agent models, Ricardian debt neutrality arises: the timing of tax collections will not affect consumption and wealth accumulation. In fact, 'life-cycle' elements have virtually no role in determining the economy's stationary capital intensity. For, consider a change in the shape of the $h(\cdot)$ or $l(\cdot)$ profile. Stationary-equilibrium aggregate wealth can continue at its old level provided we choose each family line's $A^{0}$ properly - see the proof of Proposition 2 in the appendix. In terms of fig. 2 , the $S$ curve merely slides right or left on top of itself; assuming the demand curve remains fixed, the equilibrium interest rate and $K /(\omega \cdot E)$ ratio remain unchanged. Similarly, a change in the aggregate production function will tend to leave the stationary equilibrium at $r^{*}$.

Cases with $r<r^{*}$ are more novel. Proposition 3 shows that liquidity constraints then bind at regular intervals within every family line. Consider any such instance and line. Proposition 3 shows (9)-(10) yield an $s$ such that an overall solution corresponds to: maximizing behavior between ages $s$ and $s+T$ in framework (9), beginning and ending with binding liquidity constraints; maximizing behavior over the next $T$ years, beginning and ending with binding constraints; etc. Thus in any such equilibrium 'operative' connections in every family line shrink to no more than $T$ years - leaving a sequence of short-time-horizon maximization problems. The latter problems are each reminiscent of an overlapping generations model with no altruism.

As in the overlapping generations model, Propositions' 3-4 stationary equilibria do not exhibit Ricardian debt neutrality. To see this, suppose the government decides to levy a lump sum tax today, using the proceeds to retire national debt - and promising to make lump sum transfers back to the private sector more than $T$ years in the future, financed with debt, and equaling, in present value terms, the current increment to tax revenues. With $r<r^{*}$, every family line faces binding liquidity constraints within at most $T$ years; so, given existing factor prices, complete private offsets will not occur. Rather, the old stationary state will be disrupted. ${ }^{3}$

More generally, comparative static changes in lifetime profiles of earnings or family composition will influence wealth accumulation in Proposition 3's short-horizon problems, just as in the overlapping generations model. Thus, we can expect horizontal shifts in fig. 2 - leading (see Proposition 4) to new sets of stationary equilibria. Hence, $r<r^{*}$ provides a model in which

\footnotetext{
${ }^{3}$ Equivalence properties can still hold for fiscal policies which redistribute resources between living generations - see, for example, Altig and Davis (1989).
} 
'life-cycle' attributes matter to the economy's capital intensity. (Likewise, changes in the aggregate production function will influence $r$.)

This is not to say that conventional overlapping generations formulations correctly describe behavior for equilibria with $r<r^{*}$. Using Proposition 3, we can think about family utility maximization in two ways: (a) for the age $s$ determined in Proposition 3, a line can solve its overall problem by maximizing utility from generation $i+1$ 's age $s$ to $s+T$, beginning and ending the interval with 0 assets, and then repeat the process for another interval of $T$ years, etc. $;^{4}$ or (b) the line can can solve (10) for $A^{i}, i=1,2, \ldots$, and then deduce year-by-year behavior using (9).

This paper employs approach (b). Think of first solving (10) for $A^{i}$, $i=1,2, \ldots$. Proposition 4 shows, in fact, that

$$
A^{i}=A \text { for all } i
$$

for some (unique) $A$. Second, analyze the life cycle of joint 'unit' $i$ in (9), with the $A^{i}$ and $A^{i+1}$ from (18). [Proposition 3 guarantees that either $A=0$ or the lifetime liquidity constraint in (9) will bind at one or more ages $s \in(0, T)$ for the unit'.] Differences from conventional life-cycle analyses are: joint 'units' live $T$ years (as opposed to natural families which live $2 \cdot T$ years); 'units' have family composition and earnings profiles which combine elements from a young and an old family; lifetime liquidity constraints apply to 'units' rather than single households; and 'units' may begin and end life with positive assets holdings - with (10) determining the magnitude of the latter.

\section{Total wealth accumulation}

This section presents several numerical examples. All apply to the $S$ curve in fig. 2: for a selection of given values of $r$, the tables present stationary $K_{0} /\left[w \cdot E_{0}\right]$ ratios consistent with household utility maximization. All examples assume $r<r^{*}$ - the case of Propositions 3-4. Primary findings are: (i) private stationary-equilibrium wealth accumulation tends to be very low in relation to the U.S. economy's actual performance; (ii) despite the total absence, established above, of enduring dynastic wealth holdings, quite large transfers between households appear - mainly in the form of inter vivos gifts; (iii) the transfers tend to contribute to low overall wealth accumulation by facilitating high consumption levels for young families; and (iv) binding lifetime liquidity constraints arise fairly frequently despite altruistic transfer flows - but their effects on utility tend to be much smaller than in traditional formulations.

\footnotetext{
${ }^{4}$ Notice that the family line would have needed to use (9)-(10) in concert to deduce $s$.
} 


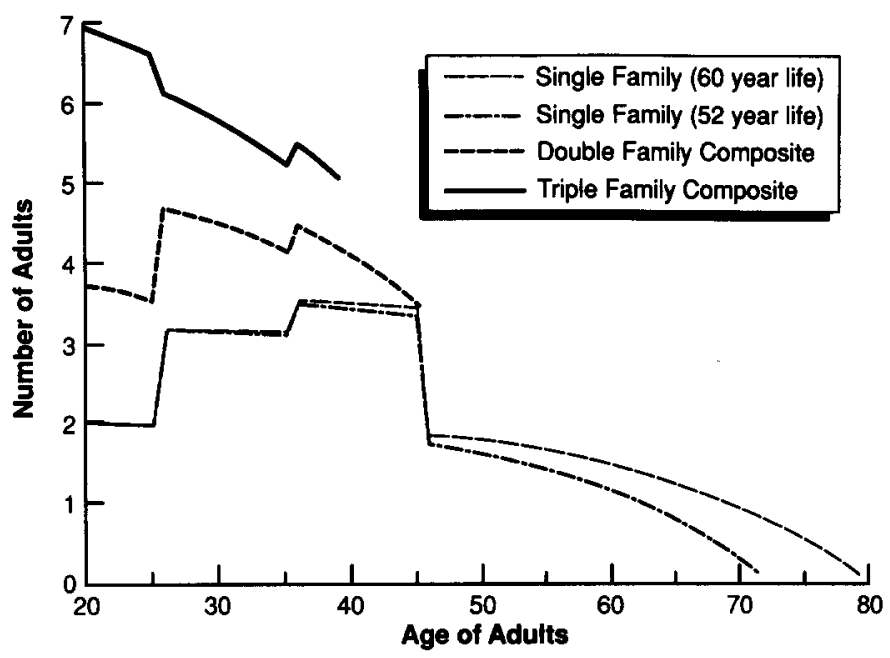

Fig. 3. Number of equivalent adults per family unit.

three generations to overlap - in our examples, a family of age $s \in[0,20]$, a parent family of age $s+20$, and a family of the parents' parents of age $s+40$. The maximum age for a family is 60 in this last case (and for a person, 80 ), and families have their children immediately (instead of after six years) so that children are ready to form their own households when their parents are 40.

A household's earnings profile has two components:

$$
l(s)=(1-\tau) \cdot l^{*}(s)+l^{* *}(s), \quad s \in[0,2 \cdot T]
$$

The first part reffects lifetime earnings and a tax rate $\tau$. As in Auerbach and Kotlikoff (1987), table 1 sets $\tau=0.15$. Table 2 tries $\tau=0.22$ - roughly the U.S. ratio of tax collections to GNP in 1972 . The profile $l^{*}(s)$ comes from median earnings by age figures for 1972 published in the Social Security Bulletin, Annual Statistical Supplement. The calculations separately multiply male and female earnings by participation rates from Employment and Earnings (1972), then by survival probabilities, and then sum them.

The second component of (19) captures social security benefits. It includes average male social security retirement benefits for 1972 (from the Social Security Bulletin, Annual Statistical Supplement) multiplied by survival probabilities, and the same for females (including retired women, wives of retired workers, and widows).

Figs. 4-7 present earnings profiles. 


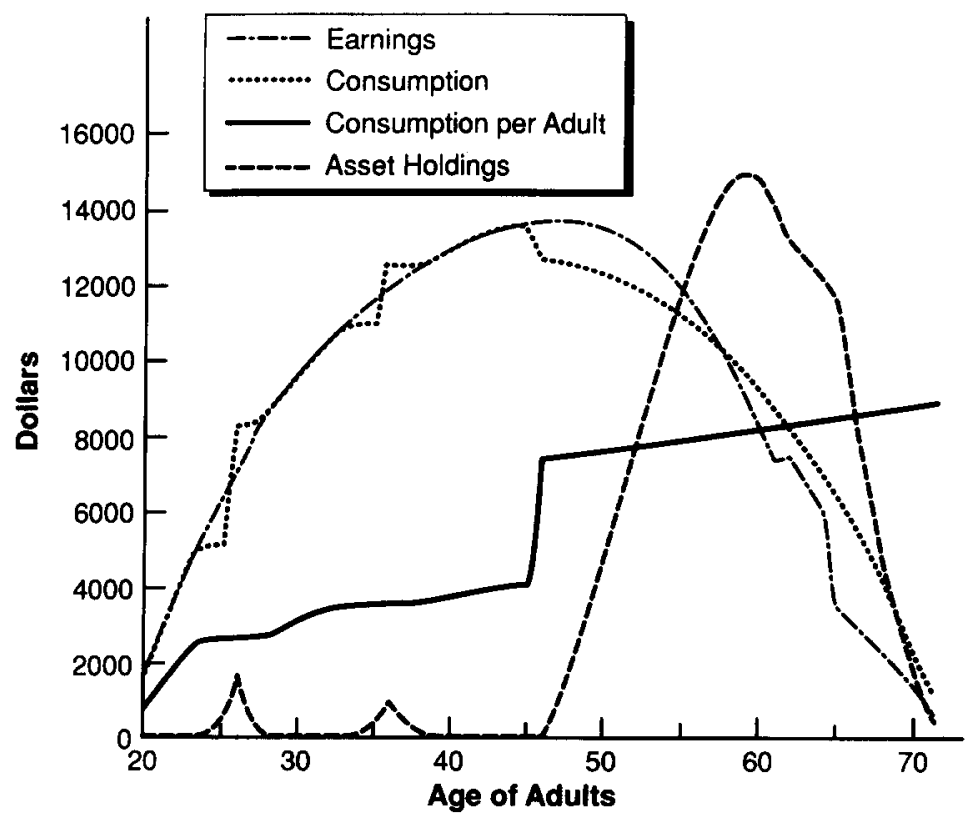

Fig. 4. Earnings, consumption, and assets for single-family unit, 52-year life.

Auerbach and Kotlikoff (1987, pp. 50-51) suggest choices $\beta=-1,-3,-9$. Table 2 tries $\delta=0$ and 0.01 . Tables 1 and $3-4$ consider $r=0,0.03,0.06$ (notice that these correspond to after-tax real interest rates).

The simulations use discrete time (with yearly periods) and normalize the wage to $1 .^{5}$ For each given $r$, they solve (10) using Bellman's (1957) 'successive approximations' ${ }^{6}$ The right-hand side of $(10)$ yields an optimizing rule

$$
A^{*}=\phi(A) \text {. }
$$

Proposition 4 shows $\phi(\cdot)$ has a single fixed point.

Using the fixed-point value for $A$, solve (9) with the algorithm from Mariger (1987). The resulting profile of lifetime asset holdings, $a(s), s=$ $1, \ldots, T$, yields a stationary wealth-to-wage bill ratio for the economy: in the

${ }^{5}$ Given isoelastic utility, to change the stationary-state wage from 1 to $w$, merely multiply all consumption and asset profiles by $w$ and all utility figures by $w^{\beta}$; given the choice of abscissa in fig. 2 , the $S$ curve is unaffected.

${ }^{6}$ In practice, the calculations used the envelope theorem and did successive approximations on the derivative of the value function. They used a grid of values for $A$ consisting of about 300 intervals. If the present value of a time- 0 family's earnings are $y$, Proposition 3 shows that the grid need only span $\left[0, y \cdot \mathrm{e}^{r \cdot T}\right]$. 


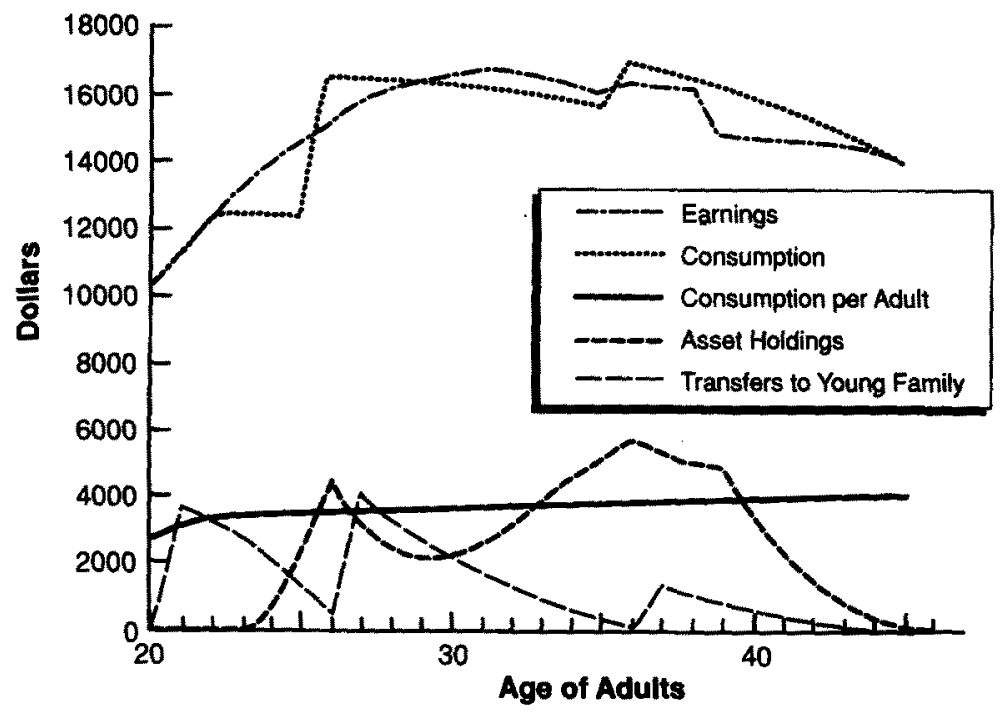

Fig. 5. Earnings, consumption, and assets for double-family unit, 26-year life,

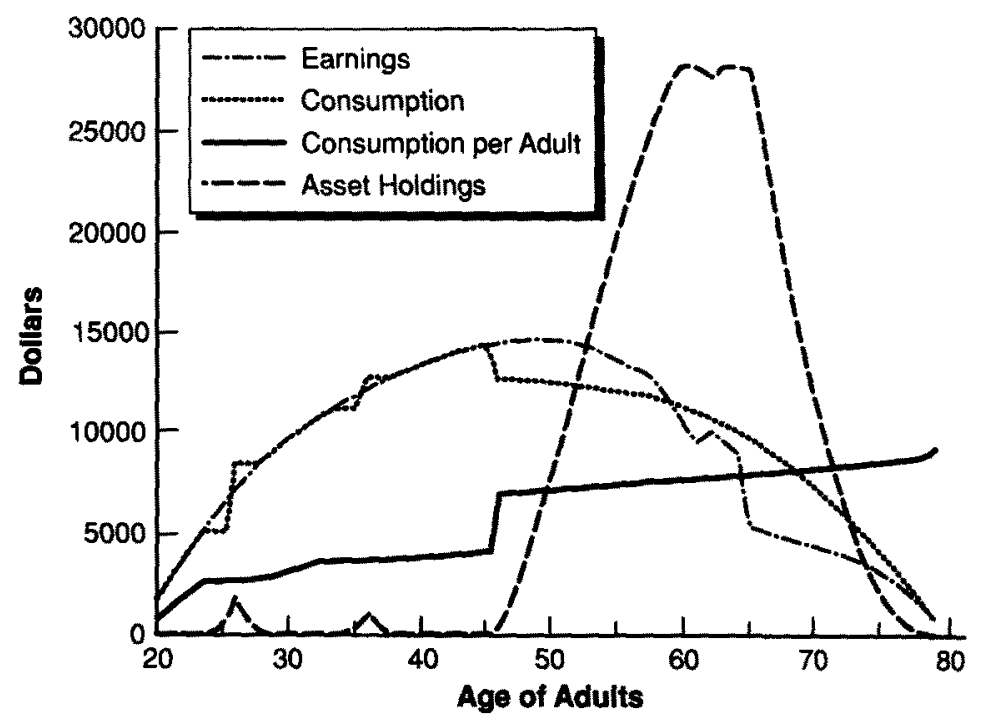

Fig. 6. Earnings, consumption, and assets for single-family unit, 60-year life. 


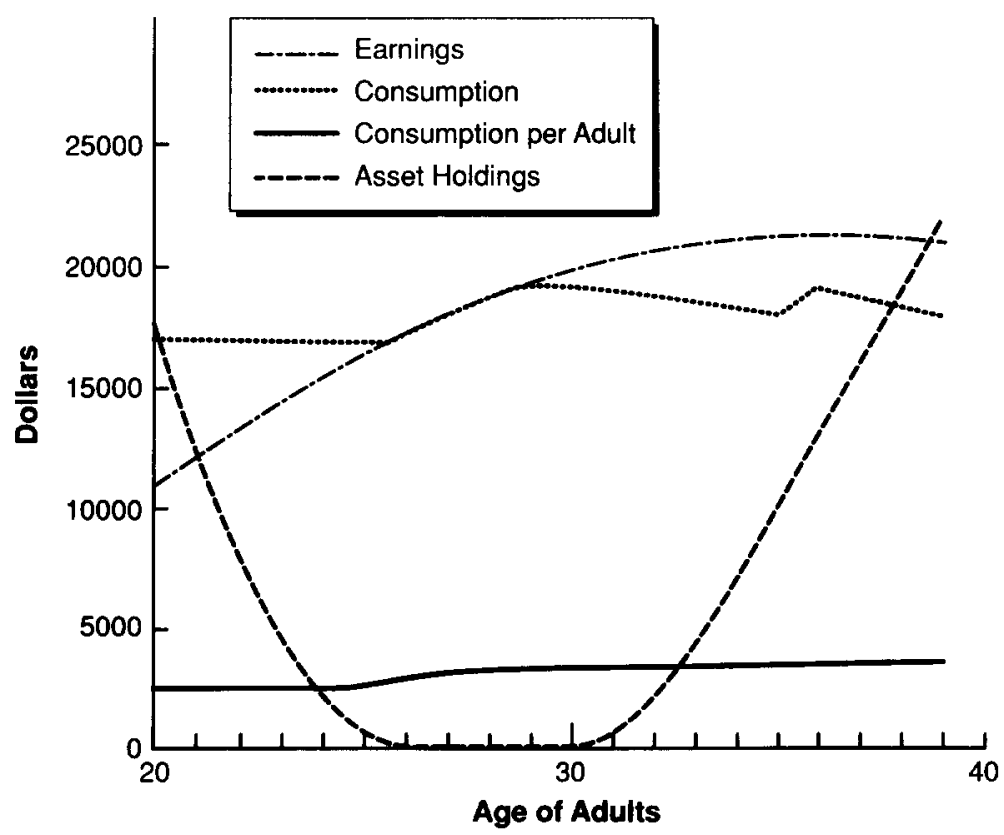

Fig. 7. Earnings, consumption, and assets for triple-family unit, 20-year life.

case of two-generation joint 'units',

$$
K /(w \cdot E)=K / E=\sum_{i=1}^{T} a(i) \cdot \mathrm{e}^{-(i-1) \cdot \gamma} / w \cdot \sum_{i=1}^{T} l^{*}(i)
$$

Since the 1972 ratio of the wage bill to GNP was about 0.6645 , the tables present

$$
K / G N P=0.6645 \cdot K /(w \cdot E)
$$

The third columns of table 1-2 include wealth-to-GNP ratios for a conventional life-cycle model (the maximum personal life span being either 72 or 80 years, depending on the trial). The fourth columns incorporate a lifetime liquidity constraint, and the fifth columns switch to the model of this paper. For comparison, adding Musgrave's (1986) 1972 figure for U.S. net reproducible private capital (4655 bil. 1982-\$), his corresponding measure of the stock of consumer durables $(740.0$ bil. $1982-\$)$, the 1972 national accounts measure of inventory stocks (612.4 bil. 1982-\$), and Seater's (1981) 1972 
market value of government debt (235.0 bil. 1982-\$) yields an empirical ratio of private wealth to GNP of 2.39 .

Clearly the simulation numbers are very small in every trial. For columns 3-4 this tends to reinforce findings from other studies - see, for example, Mariger (1986, ch. 11 and app. E).

Comparing columns 3 and 4 of tables $1-2$, lifetime liquidity constraints increase private wealth accumulation enormously. The sign changes between columns are consistent with Mariger (1986, app. E). ${ }^{7}$

As we add intergenerational altruism in column 5, we might expect that inter vivos gifts from parents to their otherwise liquidity-strapped grown children would allow the latter to spend more early in life. In turn, we might suspect that aggregate wealth would decline - moving us back toward column-3 outcomes. This intuition is borne out in most of the trials of tables $1-2 .{ }^{8}$

Figs. 4-7 present consumption profiles for families in traditional (but liquidity-constrained) life-cycle families, as well as two- and three-generation joint 'units' - as in (9). The parameter values are $\beta=-3, r=0.03, \delta=0$, and $\gamma=0.0187$. For separate families, liquidity constraints bind for almost the first half of adult life - after which consumption (per equivalent adult) jumps to a significantly higher level; for our composite units, consumption (per equivalent adult) profiles are almost flat.

Tables 3-4 show that binding lifetime liquidity constraints are fairly common for our composite units. [Recall that a composite 'unit' in table 3 (table 4) lives only half (one third) as long as a conventional family; hence, one constrained year for the former corresponds to two (three) for the latter.] This is somewhat surprising - the general shape of earnings' profiles suggests that cooperation between a young and old household might lift liquidity burdens otherwise likely to plague the former. Percentages of constrained years are not inconsistent with Campbell and Mankiw (1990), however, nor, when $r>0$, with many other papers. Furthermore, Cox and Jappelli (1990) suggest that although in practice liquidity needs and inter vivos transfer

\footnotetext{
${ }^{7}$ In comparing simulations from different sources, treatments of children, technological change, and social security often vary. Perhaps more importantly, studies sometimes derive wealth holdings at different given interest rates, as above, and sometimes add an aggregate production function and solve for $r$ endogenously. The life-cycle model's problems in generating large amounts of wealth - recall the introduction - tend to manifest themselves in the latter cases in the form of low steady-state wealth-to-GNP results, high interest rates, steep lifetime consumption profiles, and, in the absence of liquidity constraints, short periods with negative wealth [see, for instance, Tobin (1967), Mariger (1966, ch. 11), and Hubbard and Judd (1986, table 3)]. The latter will tend to lead to smaller effects from adding liquidity constraints than in tables 1-2.

${ }^{8}$ The intuition is imperfect because an intent to make an inter vivos transfer later may lead a household to save more early in life.
} 
Table 3

Double-family composites: Compensating variations for removing lifetime liquidity constraints and the magnitude of lifetime transfers (maximum adult life $\operatorname{span}=52$ years).

\begin{tabular}{|c|c|c|c|c|c|c|c|}
\hline \multirow[b]{4}{*}{ Trial } & \multirow[b]{4}{*}{ Parameters } & \multirow{2}{*}{\multicolumn{2}{|c|}{$\begin{array}{l}\text { Life-cycle model with } \\
\text { liquidity constraints }\end{array}$}} & \multicolumn{4}{|c|}{$\begin{array}{c}\text { Intergenerational life-cycle model with } \\
\text { liquidity constraints }\end{array}$} \\
\hline & & & & \multirow{3}{*}{$\begin{array}{c}\text { Years } \\
\text { binding } \\
\text { liquidity } \\
\text { con- } \\
\text { straints }\end{array}$} & \multirow[b]{3}{*}{$\begin{array}{l}\text { Compen- } \\
\text { sating } \\
\text { variation } \\
\text { ratio }^{\mathrm{a}}\end{array}$} & \multirow{2}{*}{\multicolumn{2}{|c|}{$\begin{array}{c}\text { Lifetime } \\
\text { transfer-to-GNP } \\
\text { ratio }\end{array}$}} \\
\hline & & \multirow{2}{*}{$\begin{array}{l}\text { Years } \\
\text { binding } \\
\text { liquidity } \\
\text { con- } \\
\text { straints }\end{array}$} & \multirow[b]{2}{*}{$\begin{array}{l}\text { Compen- } \\
\text { sating } \\
\text { variation } \\
\text { ratio }^{a}\end{array}$} & & & & \\
\hline & & & & & & $\begin{array}{l}\text { Transfers } \\
\text { to young } \\
\text { families }\end{array}$ & $\begin{array}{c}\text { Transfers } \\
\text { to old } \\
\text { families }\end{array}$ \\
\hline 1 & $\begin{aligned} \beta & =-1 \\
r & =0.00\end{aligned}$ & 21 & -0.203 & 10 & -0.005 & 0.058 & 0.002 \\
\hline 2 & $\begin{aligned} \beta & =-1 \\
r & =0.03\end{aligned}$ & 11 & -0.105 & 2 & -0.001 & 0.063 & 0.000 \\
\hline 3 & $\begin{aligned} \beta & =-1 \\
r & =0.06\end{aligned}$ & 5 & -0.048 & $N^{b}{ }^{b}$ & $N A^{b}$ & $\mathrm{NA}^{\mathrm{b}}$ & $N A^{b}$ \\
\hline 4 & $\begin{aligned} \beta & =-3 \\
r & =0.00\end{aligned}$ & 21 & -0.410 & 10 & -0.012 & 0.058 & 0.002 \\
\hline 5 & $\begin{aligned} \beta & =-3 \\
r & =0.03\end{aligned}$ & 19 & -0.330 & 4 & -0.005 & 0.059 & 0.000 \\
\hline 6 & $\begin{aligned} \beta & =-3 \\
r & =0.06\end{aligned}$ & 12 & -0.265 & 2 & -0.002 & 0.069 & 0.000 \\
\hline 7 & $\begin{aligned} \beta & =-9 \\
r & =0.00\end{aligned}$ & 21 & -0.684 & 10 & -0.042 & 0.058 & 0.002 \\
\hline 8 & $\begin{aligned} \beta & =-9 \\
r & =0.03\end{aligned}$ & 21 & -0.638 & 9 & -0.033 & 0.059 & 0.001 \\
\hline 9 & $\begin{aligned} \beta & =-9 \\
r & =0.06\end{aligned}$ & 20 & -0.595 & 5 & -0.028 & 0.060 & 0.003 \\
\hline
\end{tabular}

${ }^{a}$ Compensating variation divided by present value of lifetime resources.

${ }^{\mathrm{b}}$ Cases with $r>r^{*}$.

activity tend to be positively correlated, many binding constraints remain in spite of transfers.

Even if liquidity constraints bind in many periods, they need not have much of an effect on lifetime utility. Tables 3-4 present information on this in the form of compensating variations: for a family or composite unit subject to liquidity constraints, the table recomputes lifetime utility in the absence of lifetime nonnegativity restrictions (but preserving starting and ending asset figures), determining the reduction in resources in the latter case which yields lifetime utility equal to that for the constrained model. The tables list the reduction as a percentage of original lifetime resources. The figures show 
Table 4

Triple family composites: Compensating variations for removing lifetime liquidity constraints (maximum adult life span $=60$ years).

\begin{tabular}{|c|c|c|c|c|c|}
\hline \multirow[b]{2}{*}{ Trial } & \multirow[b]{2}{*}{ Parameters } & \multicolumn{2}{|c|}{$\begin{array}{l}\text { Life-cycle model with } \\
\text { liquidity constraints }\end{array}$} & \multicolumn{2}{|c|}{$\begin{array}{l}\text { Intergenerational } \\
\text { life-cycle model with } \\
\text { liquidity constraints }\end{array}$} \\
\hline & & $\begin{array}{c}\text { Years } \\
\text { binding } \\
\text { liquidity } \\
\text { constraints }\end{array}$ & $\begin{array}{l}\text { Compen- } \\
\text { sating } \\
\text { variation } \\
\text { ratio }^{a}\end{array}$ & $\begin{array}{c}\text { Years } \\
\text { binding } \\
\text { liquidity } \\
\text { constraints }\end{array}$ & $\begin{array}{l}\text { Compen- } \\
\text { sating } \\
\text { variation } \\
\text { ratio }^{\mathrm{a}}\end{array}$ \\
\hline 1 & $\beta=-1, r=0.00$ & 24 & -0.195 & 7 & -0.081 \\
\hline 2 & $\beta=-1, r=0.03$ & 15 & -0.095 & 3 & -0.060 \\
\hline 3 & $\beta=-1, r=0.06$ & 6 & -0.041 & $N_{A^{b}}^{b}$ & $\mathbf{N A}^{\mathrm{b}}$ \\
\hline 4 & $\beta=-3, r=0.00$ & 24 & -0.412 & 7 & -0.106 \\
\hline 5 & $\beta=-3, r=0.03$ & 20 & -0.331 & 5 & -0.069 \\
\hline 6 & $\beta=-3, r=0.06$ & 15 & -0.265 & 2 & -0.042 \\
\hline 7 & $\beta=-9, r=0.00$ & 24 & -0.693 & 7 & -0.164 \\
\hline 8 & $\beta=-9, r=0.03$ & 23 & -0.647 & 5 & -0.124 \\
\hline 9 & $\beta=-9, r=0.06$ & 21 & -0.602 & 5 & -0.085 \\
\hline
\end{tabular}

${ }^{a}$ Compensating variation divided by present value of lifetime resources.

that welfare losses tend to be much greater in the traditional life-cycle framework - though this is more true for table 3 than for table 4 .

Our compensating-variation results are reminiscent of outcomes in Kotlikoff and Spivak (1981). Kotlikoff and Spivak show that when no market for annuities functions (possibly because of adverse selection), individuals with independent probabilities of death can greatly mitigate their utility losses by banding together into family-sized groups in which members pool resources. Our analysis presupposes that altruism leads naturally to multifamily 'units' - section 2's maximization of (9). Tables 3-4 show that nonmarket behavior within the 'units' can drastically reduce the disutility which the absence of a market for consumption loans causes in the life-cycle formulations without altruism of column 4 .

Finally, table 3 presents simulations of the total magnitude of intergenerational transfers. Results are presented as ratios to GNP. (Thus, in trial 1, aggregate transfers from old to young families within two-family composite 'units' are about $5.8 \%$ of GNP in a stationary equilibrium with household parameter $\beta=-1$ and interest rate $r=0.00$.) The table only considers two-family joint units. The numbers emerge as follows (recall section 2). Assign initial assets (if any) exclusively to the older family in the composite of (9) (recall that beginning asset correspond to life-cycle saving carried over from age $T$ by the older family, plus any bequest from the older family's 
parents). The analysis determines a time path of consumption per equivalent adult for each unit. That and profiles of equivalent adults yield life-cycle consumption paths for young and old families. Earnings data and starting assets then imply separate asset profiles for both family types, though liquidity constraints may fail. However, starting with the composite's first age, for any year in which the young family's assets would drop below zero, assign, and record, a permanent transfer from the old family sufficient to make the young family's assets zero. The transfer, of course, reduces the only family's wealth. Similarly for transfers in the other direction. Any assets which the old family holds at the end of its life constitute a further intergenerational transfer - corresponding in practice to a bequest.

In every trial transfers from young families to old families were tiny. However, transfers from the old to the young always came out near $6 \%$ to GNP. The latter ratio is large in relation to the empirical estimate of about $2.5 \%$ in Kurz (1984), Cox (1987), and Cox and Raines (1985). [Recent work by Gale and Scholz (1991) with additional data tends to confirm the figure.] Fig. 5 shows the life-cycle pattern of transfers in one instance: they start out very high and tail off. There are three humps. Presumably the earliest stems in part from indirect costs of college - implicit in our earnings profiles. The second appears as the young family has children. The third, which is considerably smaller, appears as the latter mature into teenagers - recall Tobin's (1967) equivalent adults scales.

In the case graphed in fig. 5, the ratio of discounted earnings for an old to a young family is 0.66 , but the ratio of discounted adult equivalencies is 0.41 . For interest rates of 0 and 0.06 , the ratios are 0.55 versus 0.38 and 0.79 versus 0.45 , respectively. With Mariger's weights (see table 2) they are 0.66 versus 0.49 (and the equilibrium ratio of interfamily transfers to GNP - see the last two columns of table 3 - is 0.053 ); dropping mortality (as in table 2) they are 0.98 versus 0.67 (and the ratio of transfers to GNP is 0.050 ). One way to reduce the magnitude of intergenerational transfers in our model would be to adopt equivalency scales and earnings profiles yielding more nearly equal proportions. Another possibility would be to modify the high degree of altruism which the model assumes.

\section{Conclusion}

This paper shows that combined within the same model, liquidity constraints and altruism - each in its own right a potentially attractive addition to the analysis of saving - tend to conflict. Specifically, for a framework with homogeneous agents, Propositions $2-3$ show that in a stationary equilibrium either (i) liquidity constraints bind regularly and dynastic accumulation never 
extends beyond a half of a single life span, or (ii) liquidity constraints never bind.

In the first instance, which has received less attention in the existing literature than the second, Ricardian debt neutrality is absent and life-cycle attributes are important. Examining it in more detail, section 4 finds both similarities to and differences from traditional models without altruism.

Section 5's simulation examples investigate the same case quantitatively. Results show that altruism tends to lead to substantial inter vivos transfers from parent families to their grown children. The gifts function as a private mechanism which reduces the importance, in terms of utility, of binding lifetime liquidity constraints (though many instances of binding constraints remain).

The same intergenerational transfers tend to subvert the positive influence of life-time liquidity constraints on life-cycle wealth accumulation. Existing work showing the insufficiency of the latter in explaining total national saving is therefore reinforced.

As a topic for future research, the analysis in this paper seems to indicate that we need to allow more heterogeneity among households than just different birth dates if we are both to explain realistic amounts of wealth accumulation and to have stationary equilibria with binding liquidity constraints. Quantitative results also seem to hint that either existing measurements of inter vivos transfers tend to be too low or the degree of altruism assumed in this paper may be somewhat too high.

\section{Appendix 1: $V^{\mathrm{L}}$ and $V^{\mathrm{U}}(\cdot)$}

Let $Y^{\mathrm{U}}(t)$ be the present value at time $t$ of the remaining labor earnings of a household currently aged $T$ plus the labor earnings of its son's household for the latter's first half of life. Then

$$
Y^{\mathrm{U}}(t)=\mathrm{e}^{\gamma \cdot t} \cdot Y^{\mathrm{U}}(0) \equiv \mathrm{e}^{\gamma \cdot t} \cdot Y^{\mathrm{U}}
$$

Consider generation $i$ which is aged $T$ at time $t$. Setting $A^{j}=0$, for all $j>i$, is certainly feasible; hence,

$$
V_{i t}(A) \geq \mathrm{e}^{\beta \cdot \gamma \cdot t} \cdot V^{L} \equiv \mathrm{e}^{\beta \cdot \gamma \cdot t} \cdot \sum_{j=i}^{\infty}[\Delta \cdot T]^{(j-i)} \cdot v_{i t}(0,0) .
$$

[Note that the assumed properties of $l(\cdot)$ imply $v_{i t}(0,0)>-\infty$.] 
Given $A^{i}$, even with no lifetime consumption, $A^{j}$ is bounded above as follows: for all $j \geq i$,

$$
\begin{aligned}
& \mathrm{e}^{\gamma \cdot[t+(j-i) \cdot T]} \cdot A^{j} \leq\left[\mathrm{e}^{r \cdot T}\right]^{(j-i)} \cdot \mathrm{e}^{\gamma \cdot t} \cdot A^{i} \\
& +\sum_{k=0}^{j-i}\left[\mathrm{e}^{r \cdot T}\right]^{k} \cdot \mathrm{e}^{\gamma \cdot[t+(j-i) \cdot T-k \cdot T]} \cdot Y^{\mathrm{U}} \\
& \Leftrightarrow \\
& A^{j} \leq A^{\mathrm{U}}\left(A^{i}, j\right) \equiv\left[\mathrm{e}^{r \cdot T} / \mathrm{e}^{\gamma \cdot T}\right]^{(j-i)} \cdot A^{i}+\sum_{k=0}^{j-i}\left[\mathrm{e}^{r \cdot T} / \mathrm{e}^{\gamma \cdot T}\right]^{k} \cdot Y^{\mathrm{U}}
\end{aligned}
$$

So,

$$
V_{i t}(A) \leq \mathrm{e}^{\beta \cdot \gamma \cdot t} \cdot V^{\mathrm{U}}(A) \equiv \mathrm{e}^{\beta \cdot \gamma \cdot t} \cdot \sum_{j=i}^{\infty}[\Delta \cdot \Gamma]^{(j-i)} \cdot v\left(A^{\mathrm{U}}(A, j), 0\right)
$$

\section{Appendix 2}

Existence proof for Proposition 2

Consider any family line. Let the current time be $t=0$. Suppose generation $i$ in the line is now aged $T$. Let $\Delta \cdot \Gamma<1$. Until Step 2 let $r \leq r^{*}$.

Step 1. Suppose $\beta<0$. Then $v_{i 0}(\cdot) \leq 0$. Using (11), define

$$
v^{*}\left(A, A^{*}\right) \equiv \max \left\{v_{i 0}\left(A, A^{*}\right), V^{\mathrm{L}}-1\right\} \text {. }
$$

Then $v^{*}(\cdot)$ is bounded. (11) shows that if we substitute $v^{*}(\cdot)$ for $v_{i 0}(\cdot)$ in (10), $V_{i 0}(\cdot)$ will not be affected - maximizing behavior will never reach values of $v^{*}(\cdot)$ different from $v_{i 0}(\cdot)$.

Suppose $1>\beta>0$.

$$
r \leq r^{*}=\delta+(1-\beta) \cdot \gamma \Leftrightarrow r-\gamma \leq \delta-\beta \cdot \gamma
$$

$\Delta \cdot \Gamma<1$ implies $\delta-\beta \cdot \gamma>0$, so the right-hand side of (A.1) is positive. Hence,

$$
\beta \cdot(r-\gamma)<\delta-\beta \cdot \gamma
$$

Thus, appendix 1 shows $V^{\mathrm{U}}(A)$ in (11) is finite each $A$. We have $v_{i 0}(\cdot) \geq 0$. Set

$$
v^{*}\left(A, A^{*}\right) \equiv \min \left\{v_{i 0}\left(A, A^{*}\right), V^{\mathrm{U}}(A)+1\right\}
$$


Set $\mathscr{A} \equiv[0, \bar{A}]$ for any $\bar{A}<\infty$. Then $v^{*}\left(A, A^{*}\right)$ is bounded all $A \in \mathscr{A}$. Replacing $v_{i 0}(\cdot)$ in (10) with $v^{*}(\cdot), V_{i 0}(\cdot)$ will not be affected - as above.

The boundedness of $v^{*}\left(A, A^{*}\right)$, all $A \in \mathscr{A}$, enables us to use Theorems 4.3, 4.6, and 4.8 of Stokey and Lucas (1989). These establish that (10)-(11) have a unique solution for all $A \in \mathscr{A}, V_{i 0}(\cdot)$ is concave, and the right-hand side of (10) defines a unique policy function $[\phi(\cdot)$ in Proposition 4]. These results hold for every bounded $\mathscr{A}$.

Step 2. Now let $r=r^{*}$. Let $A^{0}$ be given.

$$
r=r^{*}=\delta+(1-\beta) \cdot \gamma \Leftrightarrow r-\gamma=\delta-\beta \cdot \gamma>0
$$

makes the present value, say, $Y$, of the our family line's labor earnings now and in all future periods finite. The proof in the text shows equalities must prevail in (13) for a stationary equilibrium. With equality, the line's optimal consumption pattern obeys [recall that $r=r^{*}$ implies $\sigma \cdot(r-\delta)=\gamma$ ]

$$
\begin{aligned}
c^{i+1}(s)+c^{i}(s+T) & =c \cdot\left[\left(h_{s} / h_{0}\right)^{\sigma}+\left(\left(h_{s+T}\right) / h_{0}\right)^{\sigma}\right] \cdot \mathrm{e}^{\sigma \cdot(r-\delta) \cdot s} \\
& \equiv c \cdot \tilde{h}_{s} \cdot \mathrm{e}^{\sigma \cdot(r-\delta) \cdot s} \\
& \equiv c \cdot \tilde{h}_{s} \cdot \mathrm{e}^{\gamma \cdot s} \text { for all } s \in[0, T],
\end{aligned}
$$

where

$$
\begin{aligned}
c & \equiv\left[Y+A^{0}\right] /\left[\sum_{i=0}^{\infty} \mathrm{e}^{(\gamma-r) \cdot i \cdot T} \cdot \int_{0}^{T} \tilde{h}_{s} \cdot \mathrm{e}^{(\gamma-r) \cdot s} \mathrm{~d} s\right] \\
& \equiv\left[Y+A^{0}\right] /\left[\sum_{i=0}^{\infty} \mathrm{e}^{(\gamma-r) \cdot i \cdot T} \cdot \tilde{h}\right] \\
& \equiv\left[Y+A^{0}\right] /[\tilde{d} \cdot \tilde{h}] .
\end{aligned}
$$

The family line will certainly avoid binding liquidity constraints over the next $T$ years [see (9)] if

$$
A^{0} \geq c \cdot \int_{0}^{t} \tilde{h}_{s} \cdot \mathrm{e}^{(\gamma-r) \cdot s} \mathrm{~d} s \text { for all } 0 \leq t \leq T .
$$

Since the integrand is nonnegative,

$$
\begin{aligned}
c \cdot \tilde{h} & =c \cdot \int_{0}^{T} \tilde{h}_{s} \cdot \mathrm{e}^{(\gamma-r) \cdot s} \mathrm{~d} s \\
& \geq c \cdot \int_{0}^{t} \tilde{h}_{s} \cdot \mathrm{e}^{(\gamma-r) \cdot s} \mathrm{~d} s \text { for all } 0 \leq t \leq T .
\end{aligned}
$$


So, (A.2) will hold if

$$
A^{0} \geq c \cdot \tilde{h}=\left(Y+A^{0}\right) / \tilde{d} .
$$

Since $\tilde{d}>1$, (A.4) will hold for large enough $A^{0}$. Let $\tilde{y}$ be the present value of our line's labor earnings over the next $T$ years. Then $Y=\tilde{d} \cdot \tilde{y}$ and

$$
\begin{aligned}
A^{1} & =\frac{\mathrm{e}^{r \cdot T}}{\mathrm{e}^{\gamma \cdot T}} \cdot\left[A^{0}+\tilde{y}-c \cdot \tilde{h}\right]=\frac{\mathrm{e}^{r \cdot T}}{\mathrm{e}^{\gamma \cdot T}} \cdot\left[A^{0}+\tilde{y}-\frac{A^{0}+Y}{\tilde{d}}\right] \\
& =\frac{\mathrm{e}^{r \cdot T}}{\mathrm{e}^{\gamma \cdot T}} \cdot\left[A^{0} \cdot \frac{\tilde{d}-1}{\tilde{d}}\right]=A^{0} .
\end{aligned}
$$

So, constraints will then not bind in the future. This and Step 1 show that an unconstrained stationary equilibrium exists.

Step 3. Let $\tilde{y}_{s} \equiv\left(l_{s}+l_{s+T}\right) \cdot w$. Our family line above will avoid constraints over the next $T$ years if and only if

$$
\begin{aligned}
& A^{0}+\int_{0}^{t} \tilde{y}_{s} \cdot \mathrm{e}^{(\gamma-r) \cdot s} \mathrm{~d} s \geq c \cdot \int_{0}^{t} \tilde{h}_{s} \cdot \mathrm{e}^{(\gamma-r) \cdot s} \mathrm{~d} s \text { for all } 0 \leq t \leq T \\
& \Leftrightarrow \\
& \lambda\left(A^{0}\right) \equiv\left[A^{0}+\int_{0}^{t} \tilde{y}_{s} \cdot \mathrm{e}^{(\gamma-r) \cdot s} \mathrm{~d} s\right]-\frac{Y+A^{0}}{\tilde{d} \cdot \tilde{h}} \cdot \int_{0}^{t} \tilde{h}_{s} \cdot \mathrm{e}^{(\gamma-r) \cdot s} \mathrm{~d} s \geq 0 .
\end{aligned}
$$

But,

$$
\lambda^{\prime}\left(A^{0}\right) \geq 1-(1 / \tilde{d})>0 .
$$

So, if $A^{0}=A$ allows an unconstrained steady state, any $A^{0} \geq A$ will too. (A.5) shows that if $A^{0}$ avoids binding constraints from 0 to $T$, the same will hold in the future. Since $\mathrm{e}^{r \cdot t} \cdot \lambda\left(A^{0}\right)$ also gives the family line's asset holdings $t$ years from now, $t \in[0, T]$, Proposition 2 is established.

\section{Proof of Proposition 4}

Consider any family line. Let the current time be $t=0$. Suppose generation $i$ in the line is now aged $T$. Let $r<r^{*}$ and $\Delta \cdot \Gamma<1$.

Step 1. Step 1 above shows (10)-(11) have a unique solution, $V_{i 0}(\cdot)$ is concave, and $\phi(\cdot)$ is uniquely determined. 
Step 2. Clearly $v_{i 0}\left(A, A^{*}\right)$ is increasing in $A$ and decreasing in $A^{*}$. The concavity of $V_{i 0}(\cdot)$ and the right-hand side of (10) then show that $\phi(\cdot)$ is nondecreasing.

Let $y$ be the present value at $t=0$ of the lifetime earnings of the joint unit in (9). Let $y^{*} \equiv \mathrm{e}^{r \cdot T} \cdot y / \mathrm{e}^{\gamma \cdot T}$. If lifetime liquidity constraints bind in (9), accounting shows $\phi(A) \leq y^{*}$. If not, $\phi(A)=0$ or Stokey and Lucas (1989, theorem 4.11) and (17) require $\phi(A)<A$. A simple graph then shows $\phi(\cdot)$ must have a fixed point $A^{\mathrm{FP}} \geq 0$ with $A^{\mathrm{FP}}=\phi\left(A^{\mathrm{FP}}\right)$. The arguments show that if $A^{1}=A^{\mathrm{FP}}$, lifetime constraints must bind during the prior $T$ years. In that case, however, $\phi\left(A^{0}\right)=A^{\mathrm{FP}}$ must be independent of $A^{0}$. Hence, $A^{\mathrm{FP}}$ is unique.

Step 3. Consider a family line with $A^{0}=A$. If lifetime liquidity constraints bind before $A^{1}$, the argument above shows $A^{1}=A^{\mathrm{FP}}$. Then $A^{i}=A^{\mathrm{FP}}$ for all $i>1$. If constraints do not bind before $A^{1}$, the arguments show $A^{1}<A^{0}$. Similarly, $A^{2}=A^{\mathrm{FP}}$ or $A^{2}<A^{1}$. Continuing, asset accumulations at every age fall as generations pass. Thus, a stationary state for the economy is only possible when $A^{i}=A^{\mathrm{FP}}$, all $i$, every family line. The last part of Proposition 4 then follows from the uniqueness of solutions to (9).

\section{References}

Altig, D. and S.J. Davis, 1989, Government debt, redistributive fiscal policies, and the interaction between borrowing constraints and intergenerational altruism, Journal of Monetary Economics 24, 3-29.

Auerbach, A.J. and L.J. Kotlikoff, 1987, Dynamic fiscal policy (Cambridge University Press, Cambridge).

Barro, R.J., 1974, Are government bonds net wealth?, Journal of Political Economy 82, 1095-1117.

Becker, G.S., 1980, Human capital and the personal distribution of income, Woytinsky lecture, in: G. Becker, Human capital (University of Chicago Press, Chicago, IL) 94-117.

Bellman, R.E., 1957, Dynamic programming (Princeton University Press, Princeton, NJ).

Blanchard, O.J. and S. Fischer, 1989, Lectures on macroeconomics (MIT Press, Cambridge, MA).

Bruce, N. and M. Waldman, 1990, The rotten-kid theorem meets the Sumaritan's dilemma, Quarterly Journal of Economics 105, 155-166.

Campbell, J.Y. and N.G. Mankiw, 1990, Permanent income, current income, and consumption, Journal of Business and Economic Statistics 8, 265-280.

Cox, D., 1987, Motives for private income transfers, Journal of Political Economy 95, 508-546.

Cox, D. and T. Jappelli, 1990, Credit rationing and private transfers: Evidence from survey data, Review of Economics and Statistics 72, 445-454.

Cox, D. and F. Raines, 1985, Interfamily transfers and income redistribution, in: M. David and T. Smeeding, eds., Horizontal equity, uncertainty, and economic well-being (University of Chicago Press, Chicago, IL) 393-421.

Denison, E.F., 1979, Accounting for slower economic growth: The United States in the 1970s (Brookings Institution, Washington, DC).

Dolde, W., 1978, Capital markets and the short run behavior of life cycle savers, Journal of Finance 33, 413-428.

Gale, W. and J. Scholz, 1991, Intergenerational transfers and the accumulation of wealth, Mimeo. (University of California, Los Angeles, CA). 
Hall, R.E., 1986, Comment, Brookings Papers on Economic Activity, 51-53.

Hall, R.E. and F.S. Mishkin, 1982, The sensitivity of consumption to transitory income: Estimates from panel data on households, Econometrica 50, 461-482.

Hayashi, F., 1985, The permanent income hypothesis and consumption durability: Analysis based on Japanese data, Quarterly Journal of Economics 100, 1083-1113.

Hori, H. and S. Kanaya, 1989, Utility functionals with nonpaternalistic intergenerational altruism, Journal of Economic Theory 49, 241-265.

Hubbard, R.G. and K.L. Judd, 1986, Liquidity constraints, fiscal policy, and consumption, Brookings Papers on Economic Activity, 1-50.

Hubbard, R.G. and K.L. Judd, 1987, Social security and individual welfare, American Economic Review 77, 630-646.

Jappelli, T., 1990, Who is credit constrained in the U.S. economy?, Quarterly Journal of Economics 105, 219-234.

Kotlikoff, L.J., 1988, Intergenerational transfers and savings, Journal and Economic Perspectives 2, 41-58.

Kotlikoff, L.J. and A. Spivak, 1981, The family as an incomplete annuities market, Journal of Political Economy 89, 372-391.

Kotlikoff, L.J. and L.H. Summers, 1981, The role of intergenerational transfers in aggregate capital accumulation, Journal of Political Economy 89, 706-732.

Kurz, M., 1984, Capital accumulation and the characteristics of private intergenerational transfers, Economica 51, 1-22.

Laitner, J., 1988, Bequests, gifts, and social security, Review of Economic Studies 55, 275-300.

Laitner, J., 1991, Modeling marital connections among family lines, Journal of Political Economy 99, 1123-1141.

Lindbeck, A. and J.W. Weibull, 1988, Altruism and time consistency: The economics of fait accompli, Journal of Political Economy 96, 1165-1182.

Loury, G.C., 1981, Intergenerational transfers and the distribution of earnings, Econometrica 49 , 843-867.

Mariger, R.P., 1986, Consumption behavior and the effects of government fiscal policies (Harvard University Press, Cambridge, MA).

Mariger, R.P., 1987, A life-cycle consumption model with liquidity constraints: Theory and empirical results, Econometrica 55, 533-558.

Musgrave, J., 1986, Fixed reproducible tangible wealth in the United States: Revised estimates, Survey of Current Business 66, 51-75.

Seater, J., 1981, The market value of outstanding government debt: 1919-1975, Journal of Monetary Economics 8, 85-101.

Stokey, N. and R.E. Lucas, 1989, Recursive methods in economic dynamics (Harvard University Press, Cambridge, MA).

Strotz, R., 1956, Myopia and inconsistency in dynamic utility maximization, Review of Economic Studies 23, 165-180.

Tobin, J., 1967, Life cycle saving and balanced growth, in: W. Fellner, ed., Ten economic studies in the tradition of Irving Fisher (Wiley, New York, NY) 231-256.

U.S. Department of Health and Human Services, Social Security Administration, 1972, Social security bulletin, Annual statistical supplement (U.S. Government Printing Office, Washington, DC).

U.S. Department of Labor, Bureau of Labor Statistics, 1972, Employment and earnings (U.S. Government Printing Office, Washington, DC).

Yotsuzuka, T., 1987, Ricardian equivalence in the presence of capital market imperfections, Journal of Monetary Economics 20, 411-436.

Zeldes, S., 1989, Consumption and liquidity constraints: An empirical investigation, Journal of Political Economy 97, 305-346. 